\title{
Latitudinal variation of foF2 hysteresis of solar cycles 20,21 and 22 and its application to the analysis of long-term trends
}

\author{
N. Ortiz de Adler ${ }^{1}$ and A. G. Elias ${ }^{1,2}$ \\ ${ }^{1}$ Laboratorio de Física de la Atmósfera, Departamento de Física, Facultad de Ciencias Exactas y Tecnología, Universidad \\ Nacional de Tucumán, Av. Independencia 1800, 4000 Tucuman, Argentina \\ ${ }^{2}$ Consejo Nacional de Investigaciones Científicas y Técnicas, CONICET, Argentina
}

Received: 11 May 2007 - Revised: 7 September 2007 - Accepted: 13 December 2007 - Published: 28 May 2008

\begin{abstract}
Noon $f_{o} \mathrm{~F} 2$ monthly median values for equinoctial months of solar cycles 20, 21 and 22, were analyzed for 37 worldwide stations. For each solar cycle and for a given $R_{z}$, the difference between $f o \mathrm{~F} 2$ in the falling branch of the cycle and the corresponding value of the rising branch is evaluated. The maximum difference, considered as the hysteresis magnitude, varies systematically with geomagnetic latitude. The pattern is similar for every cycle, with greater hysteresis magnitudes for stronger solar cycles. It is positive between $45^{\circ} \mathrm{S}$ and $45^{\circ} \mathrm{N}$, with minimum values at equatorial latitudes and maximum at around $25^{\circ}-30^{\circ}$ on either side of the equator. For latitudes greater than $50^{\circ}$ negative values are observed. At around $25^{\circ}-30^{\circ}$ and at high latitudes the hysteresis magnitude reaches $2 \mathrm{MHz}$ for solar cycle with high activity levels, which represents around $20 \%$ of $f o \mathrm{~F} 2$. The effects of $f o \mathrm{~F} 2$ hysteresis on the analysis of long-term data sequences is analyzed. In the case of long-term trend analysis, the hysteresis behavior may induce spurious trends as a consequence of the filtering processes applied to $f o \mathrm{~F} 2$ time series previous to trend values estimation. This problem may be solved by considering time series covering several solar cycles.
\end{abstract}

Keywords. Ionosphere (Ionospheric disturbances; General or miscellaneous)

\section{Introduction}

The F2 critical frequency $f o \mathrm{~F} 2$, for a given station and a constant value of the solar activity level, such as the sunspot number $R_{z}$, can differ for the rising and falling parts of the 11 -year solar cycle. The variation of $f_{o} \mathrm{~F} 2$ over a complete solar cycle displays a curve similar to the hysteresis variation of a magnetization cycle. The enhanced geomagnetic activ-

Correspondence to: A. G. Elias

(anagelias@yahoo.com) ity during the falling phase of the solar cycle would produce stronger F2 layer storm effects.

The phenomenon of ionospheric hysteresis has been known for a long time (Naismith and Smith, 1961; Naismith et al., 1961; Huang, 1963; Rao and Rao, 1969; Muggleton, 1969; Smith and King, 1981). Rao and Rao (1969), considering noon $f o \mathrm{~F} 2$ values, evaluated the magnitude of the hysteresis of solar cycle 19 (1954-1964) by the area between rising and falling parts of the solar cycle, and reported its dependence on geomagnetic latitude with maximum magnitude values at mid-latitudes (around $25^{\circ}$ ) and minimum values at equatorial and high latitudes. The observed latitudinal variation indicate a geomagnetic control of the hysteresis phenomenon.

Apostolov and Alberca (1995) analyzed the seasonal variation of the $f o \mathrm{~F} 2$ hysteresis area for Slough $\left(51.5^{\circ} \mathrm{N}, 0.6^{\circ} \mathrm{W}\right)$ of solar cycles 17 (1933-1944) to 21 (1976-1986). The annual variation, with maxima near the equinoxes, supports the idea of the geomagnetic control of this phenomenon. This idea is also suggested by Mikhailov and Mikhailov (1995) who attribute the hysteresis to the behavior of geomagnetic activity throughout the solar cycle.

Buresova and Lastovicka (2000) analyzed the $f o \mathrm{~F} 2$ hysteresis for solar cycles 20 (1964-1976) and 21 (1976-1986) estimating its magnitude as the difference between $f o \mathrm{~F} 2$ values of years just before and just after the solar cycle minimum since they expect the most pronounced hysteresis near the minimum solar activity epoch.

In the present work, the variation of $f o \mathrm{~F} 2$ hysteresis magnitude with geomagnetic latitude is analyzed using data of 37 worldwide ionospheric stations of solar cycles 20 (19641976), 21 (1976-1986) and 22 (1986-1996). The hysteresis magnitude in our case is the maximum difference between $f_{o} \mathrm{~F} 2$ in the falling branch of the cycle and the corresponding value at the same activity level of the rising branch. The possibility that a $f o \mathrm{~F} 2$ hysteresis behavior may affect long-term trend estimation is discussed.

Published by Copernicus Publications on behalf of the European Geosciences Union. 
Table 1. Ionospheric stations analyzed in the present work (World Data Center for Solar Terrestrial Physics, WDC1 in England, Data Archives).

\begin{tabular}{|c|c|c|c|c|}
\hline Station & $\begin{array}{c}\text { Geographic } \\
\text { latitude } \\
\left({ }^{\circ} \mathrm{N}\right)\end{array}$ & $\begin{array}{c}\text { Geographic } \\
\text { longitude } \\
\left({ }^{\circ} \mathrm{W}\right)\end{array}$ & $\begin{array}{c}\text { Geomagnetic } \\
\text { latitude } \\
\left({ }^{\circ} \mathrm{N}\right)\end{array}$ & $\begin{array}{c}\text { Geomagnetic } \\
\text { longitude } \\
\left({ }^{\circ} \mathrm{W}\right)\end{array}$ \\
\hline Ahmedabad & 23.0 & 72.6 & 13.8 & 214.8 \\
\hline Akita & 39.7 & 140.1 & 29.8 & 206.8 \\
\hline Alma Ata & 43.3 & 76.9 & 33.5 & 151.9 \\
\hline Argentine Islands & -65.2 & 295.7 & -54.0 & 4.4 \\
\hline Argentia & 47.3 & 306.0 & 58.9 & 21.6 \\
\hline Arkhangelesk & 64.6 & 40.5 & 58.7 & 129.1 \\
\hline Ashkabad & 37.9 & 58.3 & 30.4 & 134.5 \\
\hline Athens & 38.0 & 23.6 & 36.4 & 102.5 \\
\hline Boulder & 40.0 & 254.7 & 48.9 & 318.7 \\
\hline Brisbane & -27.5 & 152.9 & -35.4 & 228.3 \\
\hline Budapest & 47.4 & 19.2 & 45.9 & 101.3 \\
\hline Camden & -34.0 & 150.7 & -42.0 & 227.6 \\
\hline Campbell & -52.5 & 169.2 & -57.1 & 254.4 \\
\hline Canberra & -35.3 & 149.0 & -43.7 & 225.7 \\
\hline Casey & -66.3 & 110.5 & -77.6 & 178.2 \\
\hline Christchurch & -43.6 & 172.8 & -47.7 & 253.5 \\
\hline Concepcion & -36.6 & 287.0 & -25.5 & 357.6 \\
\hline Dakar & 14.8 & 341.6 & 21.4 & 56.0 \\
\hline Darwin & -12.5 & 131.0 & 22.9 & 202.7 \\
\hline Dourbes & 50.1 & 4.6 & 51.7 & 88.9 \\
\hline Grahamstown & -33.3 & 26.5 & -33.9 & 89.4 \\
\hline Huancayo & -12.0 & 284.7 & 0.7 & 355.2 \\
\hline Johannesburg & -26.1 & 28.1 & -27.2 & 92.8 \\
\hline Kodaikanal & 10.2 & 77.5 & 0.6 & 148.5 \\
\hline Mundaring & -32.0 & 116.3 & -43.2 & 187.7 \\
\hline Okinawa & 26.3 & 127.8 & 15.5 & 196.9 \\
\hline Poitiers & 46.6 & 0.4 & 49.2 & 83.0 \\
\hline Port Stanley & -51.7 & 302.2 & -40.6 & 10.3 \\
\hline Rome & 41.8 & 12.5 & 42.3 & 93.2 \\
\hline Slough & 51.5 & 359.4 & 54.0 & 84.4 \\
\hline Sodankyla & 67.4 & 26.6 & 63.6 & 120.8 \\
\hline Tahiti & -17.7 & 210.7 & -15.2 & 284.4 \\
\hline Taipei & 25.0 & 121.5 & 13.8 & 190.9 \\
\hline Tomsk & 56.5 & 84.9 & 46.0 & 160.6 \\
\hline Uppsala & 59.8 & 17.6 & 58.3 & 106.9 \\
\hline Vanimo & -2.7 & 141.3 & 12.3 & 212.5 \\
\hline Yamagawa & 31.2 & 130.6 & 20.6 & 199.1 \\
\hline
\end{tabular}

\section{Data analysis}

Noon $f o F 2$ monthly median data from 37 ionosonde worldwide stations, available at the World Data Center for Solar Terrestrial Physics, WDC1 in England, were analyzed. The stations, listed in Table 1, were selected according to the completeness of its $f o \mathrm{~F} 2$ records. The equinoctial months (April, March, September and October), when the hysteresis is expected to be best developed, were analyzed.

In the present work, the hysteresis magnitude was estimated as the maximum difference during a given solar cy- cle, between $f_{o} \mathrm{~F} 2$ value in the falling phase and the corresponding value in the rising phase for a constant $R_{z}$. Figure 1 shows, as an example, the foF 2 hysteresis (points in the scatterplot of $f_{o} \mathrm{~F} 2$ vs. $R_{z}$ joined chronologically) for three ionospheric stations. The hysteresis magnitude is shown as a vertical dashed line. Its value, in $\mathrm{MHz}$, corresponds to the maximum $f o \mathrm{~F} 2$ difference between the rising and the falling branch of the hysteresis for a given $R_{z}$ value. Within a solar cycle, we considered every foF 2 point (in the rising and falling phases of the solar cycle) and calculated the difference between it and the corresponding value in the falling phase 


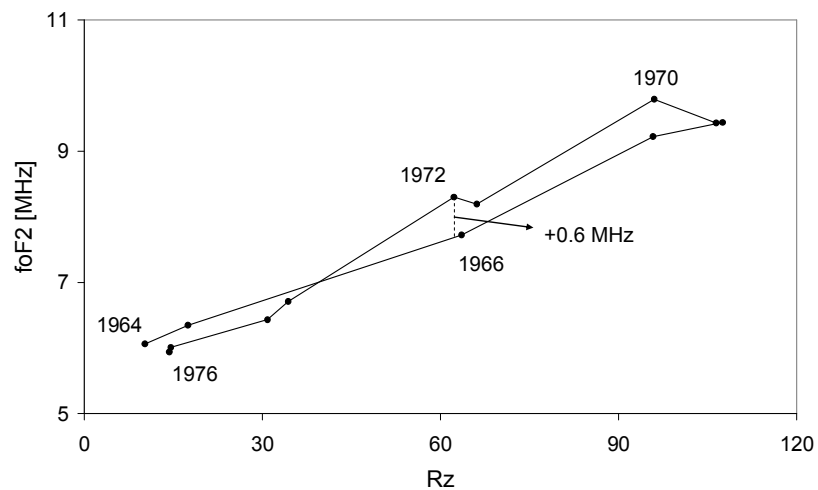

(a)

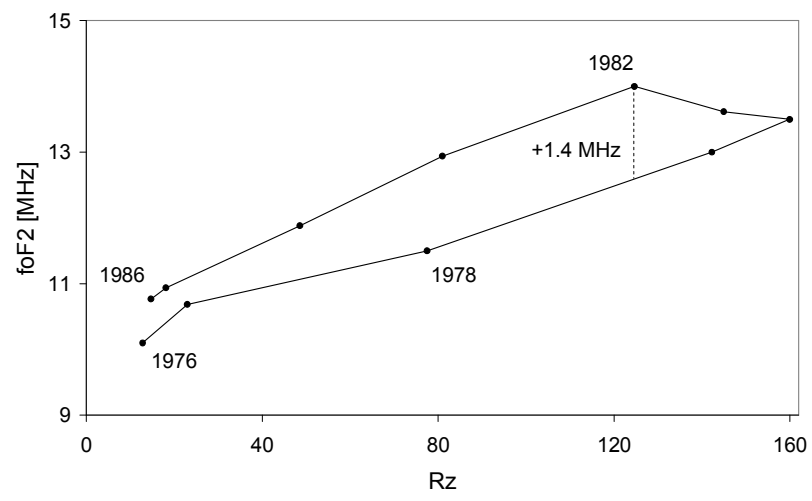

(b)

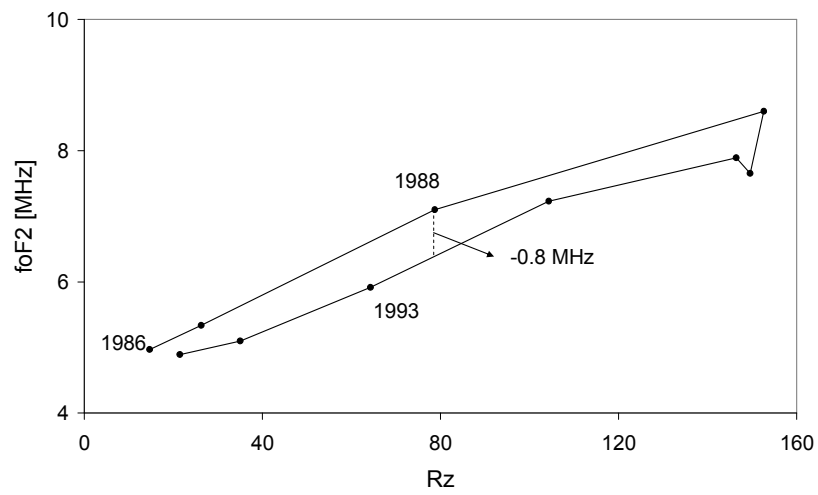

(c)

Fig. 1. Monthly median $f o \mathrm{~F} 2$ at noon in terms of $R_{z}$ for (a) Mundaring in September during solar cycle 20 (b) Ahmadabad in April during solar cycle 21 and (c) Argentine Islands in April during solar cycle 22 . The vertical dashed line indicate the maximum amplitude of the hysteresis which is given in $\mathrm{MHz}$.

(if the considered foF 2 point is in the rising phase) or in the rising phase (if the $f_{o} \mathrm{~F} 2$ point is in the falling phase). The positive sign corresponds to a higher foF2 value at the falling than at the rising phase of the cycle, and the negative sign, to a higher $f_{o} \mathrm{~F} 2$ value at the rising phase. Usually, the values of the monthly $R_{z}$ time series during a solar cycle phase do not

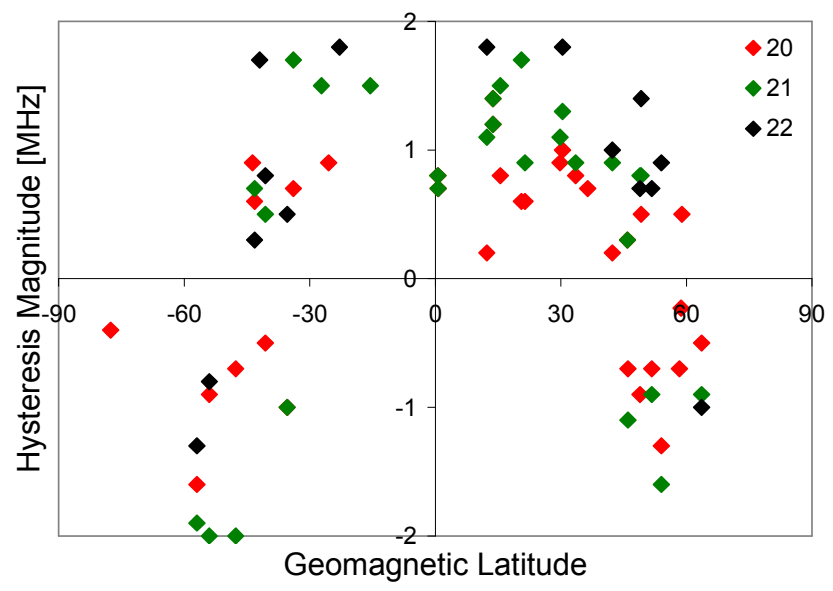

Fig. 2. $f o \mathrm{~F} 2$ hysteresis magnitude (maximum difference during a given solar cycle between foF 2 value in the falling phase and the corresponding value in the rising phase for a constant $R_{z}$ ) for solar cycles 20 (red diamonds), 21 (green diamonds) and 22 (black diamonds).

coincide with the values during the other phase of the same cycle, so that the required $f o \mathrm{~F} 2$ value was assessed from a linear interpolation between the pair of $\left(f \circ \mathrm{F} 2, R_{z}\right)$ points whose interval contains the $R_{z}$ value needed. The hysteresis magnitude corresponds, within a solar cycle, to the maximum foF2 difference thus estimated.

The hysteresis magnitude for solar cycles 20 (1964-1976), 21 (1976-1986) and 22 (1986-1996) (maximum $R_{z}: 136$, 188 and 200, respectively) are shown in Fig. 2. The latitudinal pattern for cycles 20 and 21 presents maximum magnitude values at latitudes around $25^{\circ}-30^{\circ}$ and at high latitudes, and minimum values around the equator and at latitudes around $45^{\circ}-50^{\circ}$. The latitudinal pattern of solar cycle 22 is similar except for the lack of data at the equator.

\section{Analysis of long-term foF2 data sequences presenting hysteresis}

In long-term trend assessments the hysteresis may induce spurious trends in filtering processes. As the ionosphere seems to be sensitive to climate variations (Rishbeth, 1990; Rishbeth and Roble, 1992), trend assessments in ionospheric parameters have gained importance in studies related to climate change, which try to elucidate the origin (natural or anthropogenic) of global warming. foF2 long-term trend estimations, are based on a previous filtering of the $f_{o} \mathrm{~F} 2$ data series which relies on a linear relationship with solar activity. An hysteresis behavior may induce in this case a spurious trend. As an example, Fig. 3 shows an artificial hysteresis of $y$ in terms of $x$ during a single cycle. If $x$ is linearly filtered from $y$, a trend is detected in $y$ only as a result of the filter used. This spurious trend can be offset as one considers more 


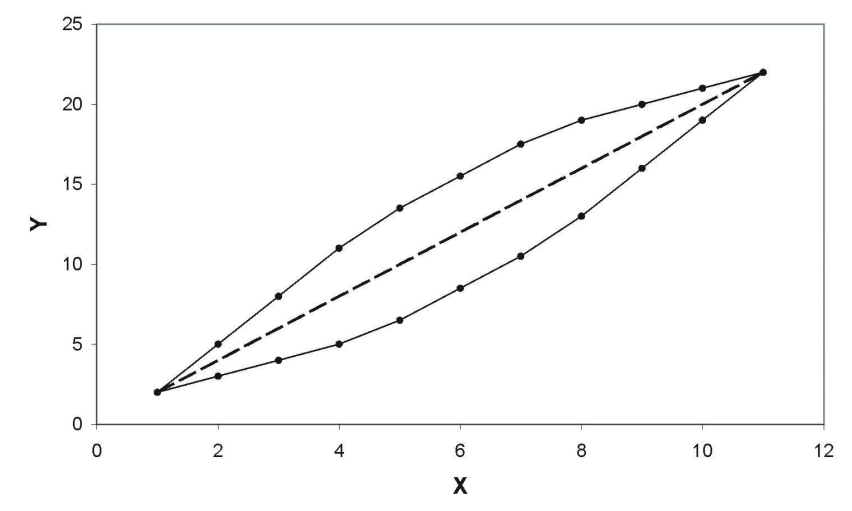

Fig. 3. Artificial hysteresis of $y$ in terms of $x$ during a single cycle (solid line) and the "ideal" linear function of $y$ in terms of $x$ during the same cycle (dashed line).

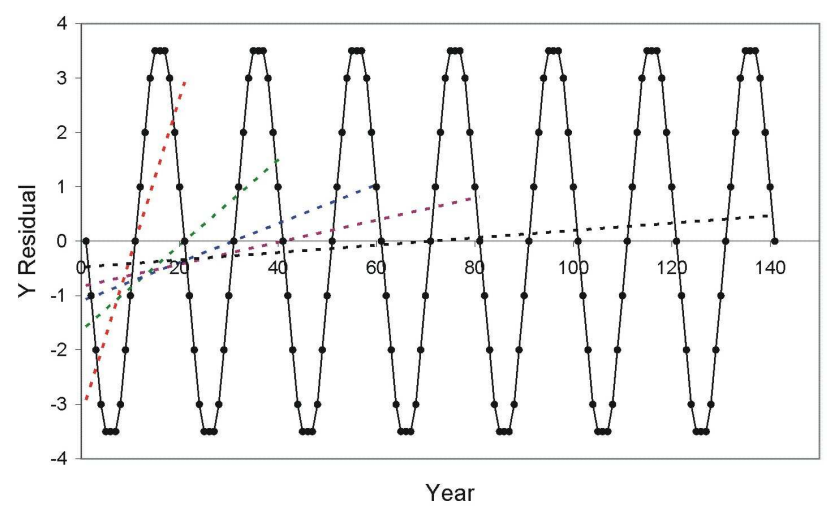

Fig. 4. $y$ (during several cycles) after filtering $x$ using a linear filter (solid black line), and the linear trends obtained if only one cycle is used (red dashed line), two (green dashed line), three (blue dashed line), and following on.

cycles in the trend estimation (as can be seen in Fig. 4) or, as suggested by Danilov and Mikhailov (1999), using only the points around the maximum and minimum of a cycle.

Figure 5 shows two real cases where the linear trend of foF2 for two stations here analyzed (Slough and Argentine Islands) was estimated considering just one solar cycle, then two, and finally three.

As a first step in assessing trends, the solar activity variation has to be filtered out from $f o \mathrm{~F} 2$ data series. This was done estimating the residuals of a linear fit between $f o \mathrm{~F} 2$ and a solar activity proxy ( $R_{z}$ in our case), that is

$f o \mathrm{~F} 2$ residual $=f o \mathrm{~F} 2_{\exp }-f o \mathrm{~F} 2_{\text {mod }}$

where $f o \mathrm{~F} 2_{\text {exp }}$ is the experimental data and $f o \mathrm{~F} 2_{\text {mod }}$ is $f o \mathrm{~F} 2$ modeled through a linear regression with $R_{z}$. Then, the linear trend $(\alpha)$ was estimated through least squares from

$f o \mathrm{~F} 2$ residual $=\alpha$ year $+\beta$

As in the ideal case shown in Fig. 3 , in Fig. 5 it can be noticed how the slope of the trend, that is $\alpha$, decreases as more cycles

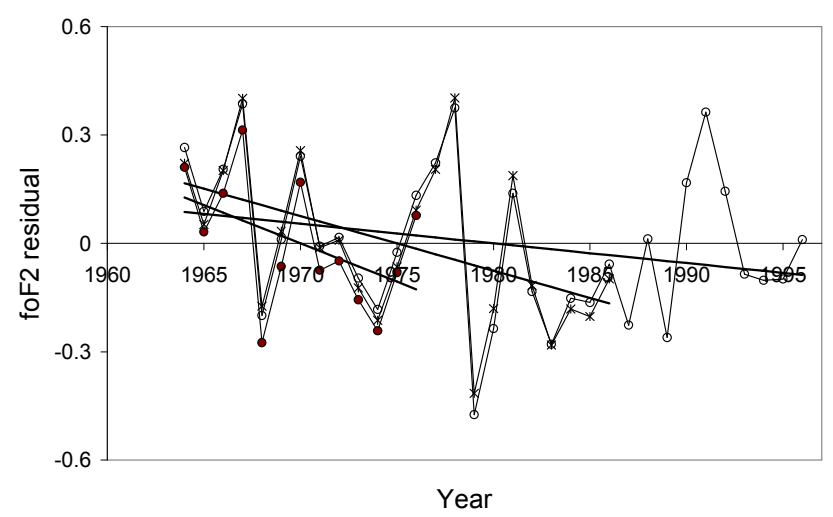

(a)

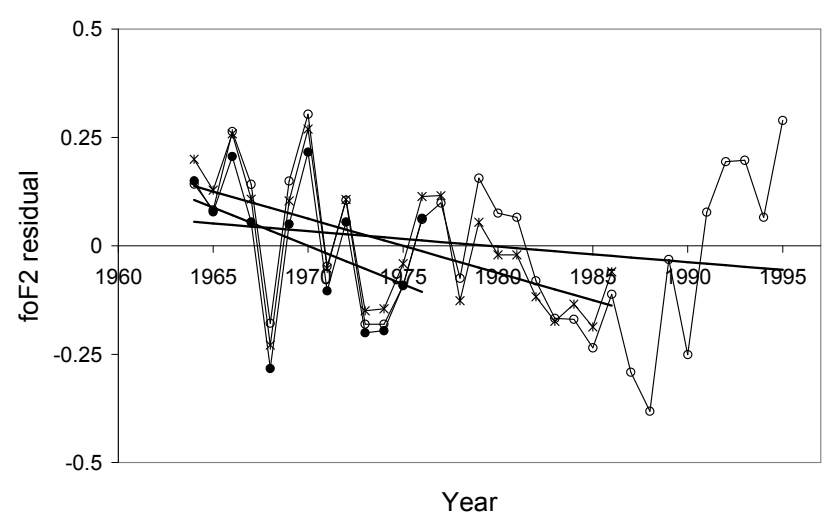

(b)

Fig. 5. Time series of $f o \mathrm{~F} 2$ residuals and long term trend (enhanced line) considering solar cycle 20 (solid circle), solar cycles $20+21$ (asterisk) and solar cycles $20+21+22$ (empty cicrcle) for noon values (a) in September at Slough and (b) in April at Argentine Islands.

are considered for trend estimation. In the case of Slough, $\alpha$ is $-0.02 \mathrm{MHz} /$ year when only solar cycle 20 is considered, $-0.015 \mathrm{MHz} /$ year when solar cycles 20 and 21 are considered, and $-0.005 \mathrm{MHz} /$ year when solar cycles 20, 21 and 22 are considered. In the case of Argentine Islands these values are $-0.02,-0.012$ and $-0.004 \mathrm{MHz} /$ year, respectively.

\section{Discussion}

The hysteresis magnitude for solar cycles 20 (1964-1976), 21 (1976-1986) and 22 (1986-1996) estimated in this work as a difference, and that obtained by Rao and Rao (1969) for solar cycle 19 (1954-1964) but assessed as the area, present similar latitudinal patterns. Except that, in our case, negative values at high latitudes are as important as the positive values around mid-latitudes.

The latitudinal pattern of the hysteresis magnitude is similar in shape to that of $f o \mathrm{~F} 2$ diurnal mean values, which shows a pronounced trough at the magnetic equator and crests at about $30^{\circ} \mathrm{N}$ and $30^{\circ} \mathrm{S}$ magnetic dip (equatorial anomaly). 
The hysteresis magnitude increases with solar activity. As an example, for Ashkabad $\left(30.4^{\circ} \mathrm{N}\right)$ the hysteresis magnitude for cycles 20,21 and 22 are $1,1.3$ and $1.8 \mathrm{MHz}$, respectively. At $25^{\circ}-30^{\circ}$ and at high latitudes it can reach $2 \mathrm{MHz}$ for the solar cycle with high activity level, which represents around $20 \%$ of $f_{o} \mathrm{~F} 2$.

The latitudinal pattern of the hysteresis magnitude may be compatible with the idea of a geomagnetic control for each of the solar cycles here analyzed (20 to 22), and also during cycle 19 (shown by Rao and Rao, 1969). Geomagnetic disturbances are accompanied by large changes in the ionospheric F2 layer, but neither the morphology nor the physics is fully known. The ionospheric response to geomagnetic activity is highly complex due to the many physical processes involved. However there are underlying trends that are useful in characterizing the ionosphere response to storms in a relatively simple way (Fuller-Rowell et al., 2000; Araujo-Pradere et al., 2002). The picture widely used regarding the latitudinal pattern of ionospheric storms is the following: mainly negative storms at high latitudes and more prevalent positive storms at mid and low latitudes (Rishbeth and Field, 1997; Field and Rishbeth, 1997). Taking into account that geomagnetic activity is higher on average during the descending phase of the solar cycle than during the ascending phase, a clockwise or counter-clockwise hysteresis should be expected at a location depending on its prevalent negative or positive ionospheric storms. By clockwise or counter-clockwise we mean the path followed by joining the points in an $f_{o} \mathrm{~F} 2$ vs. $R_{z}$ plot, begining at the year of the first minimum of the cycle and ending at the year of the following minimum. In terms of the hysteresis magnitude here estimated, this implies negative or positive hysteresis magnitude, respectively. This consideration leads to a latitudinal pattern of hysteresis magnitude highly consistent with the pattern we observe.

Although the phenomenon of ionospheric hysteresis has been known for a long time, a linear relationship between $f_{o} \mathrm{~F} 2$ and $R_{z}$ is used in forecasting and long-term trend estimations.

Models used in ionospheric condition predictions for radiowave propagation do not consider the foF2 hysteresis effect. However, according to our results, hysteresis magnitudes as high as $2 \mathrm{MHz}(20 \%$ of $f o \mathrm{~F} 2$ mean values for certain ionospheric stations) can occur for strong solar cycles and at mid-latitudes.

In long-term trends analysis the hysteresis may induce spurious trends due to the filtering processes applied to $f_{o} \mathrm{~F} 2$ time series previous to trend values estimation. As shown here, this problem can be partially solved by considering long time series covering several solar cycles; at least more than one.

Acknowledgements. This work has been supported by the CIUNT Project "The solar engine and its influence on the atmosphere and climate" directed by N. Ortiz de Adler. A. G. Elias thanks J. Lastovicka, T. Ulich and the Local Organizing Committee of the 4th
Workshop on Long-Term Changes and Trends in the Atmosphere, for the financial support provided to attend the Workshop and present this work.

Topical Editor M. Pinnock thanks C. J. Davis and M. Pinnock for their help in evaluating this paper.

\section{References}

Apostolov, E. M. and Alberca, L. F.: foF2 hysteresis variations and the semi-anual geomagnetic wave, J. Atmos. Terr. Phys., 57, 755-757, 1995.

Araujo-Pradere, E. A., Fuller-Rowell, T. J., and Codrescu, M. V.: STORM: An empirical storm-time ionospheric correction model 1. Model description, Radio Sci., 37, 1070, doi:10.1029/2001RS002467, 2002.

Danilov, A. D. and Mikhailov, A. V.: Spatial and seasonal variations of the $f o \mathrm{~F} 2$ long-term trends, Ann. Geophys., 17, 1239-1243, 1999, http://www.ann-geophys.net/17/1239/1999/.

Field, P. R. and Rishbeth, H.: The response of the ionospheric F2layer to geomagnetic activity: an analysis of worldwide data, J. Atmos. Solar Terr. Phys., 59, 163-180, 1997.

Fuller-Rowell, T. J., Codrescu, M. C., and Wilkinson, P.: Quantitative modeling of the ionospheric response to geomagnetic activity, Ann. Geophys., 18, 766-781, 2000, http://www.ann-geophys.net/18/766/2000/.

Huang, Y. N.: The hysteresis variation of the semi-thickness of the F2-layer and its relevant phenomenon at Kokobunji, Japan, J. Atmos. Terr. Phys., 25, 647-658, 1963.

Mikhailov, A. V. and Mikhailov, V. V.: Solar cycle variations of annual mean noon $f o$ F2, Adv. Space Res., 15, 79-82, 1995.

Muggleton, L. M.: Secular variation in F-region response to sunspot number, J. Atmos. Terr. Phys., 31, 1413-1419, 1969.

Naismith, R. and Smith, P. A.: Further evidence of a long-term variation in the relationship of solar activity to the ionosphere, J. Atmos. Terr. Phys., 22, 270-274, 1961.

Naismith, R., Bevan, H. C., and Smith, P. A.: A long term variation in the relationship of sunspot numbers to E-region character figures, J. Atmos. Terr. Phys., 21, 167-173, 1961.

Rao, M. S. V. G. and Rao, R. S.: The hysteresis variation in F2-layer parameters, J. Atmos. Terr. Phys., 31, 1119-1125, 1969.

Rishbeth, H.: A greenhouse effect in the ionosphere?, Planet. Space Sci., 38, 945-948, 1990.

Rishbeth, H. and Roble, R. G.: Cooling of the upper atmosphere by enhanced greenhouse gases. Modeling of the thermospheric and ionospheric effects, Planet. Space Sci., 40, 1011-1026, 1992.

Rishbeth, H. and Field, P. R.: Latitude and solar-cycle patterns in the response of the ionosphere F2-layer to geomagnetic activity, Adv. Space Res., 20, 1689-1692, 1997.

Smith, P. A. and King, J. W.: Long-term relationships between sunspots, solar faculae and the ionosphere, J. Atmos. Terr. Phys., 43, 1057-1063, 1981. 